\title{
Correspondence
}

To the Editors

\section{COVID-19 lock down and impact on rotavirus incidence: a reappraisal}

Sri Lanka Journal of Child Health, 2020; 49(4): 416

DOI: http://dx.doi.org/10.4038/sljch.v49i4.9284

(Key words: COVID-19, infection, rotavirus, control, lockdown, pandemic)

COVID-19 is an important pandemic at present affecting many millions of patients worldwide. A standard measure for COVID-19 containment is strict infection control by implementing lock down measures. The strict control is aimed at reducing the incidence of COVID-19. Additionally, the stringent control can also impact the incidence of other diseases such as influenza ${ }^{1}$. The situation in Thailand, an Indochina country, is the best example ${ }^{1}$.

The authors reappraised the public data on the effect of COVID-19 lock down on the incidence of an important paediatric disease, rotavirus infection. Rotavirus is a gastrointestinal pathogen that is transmitted via contaminated food and water ${ }^{2}$.

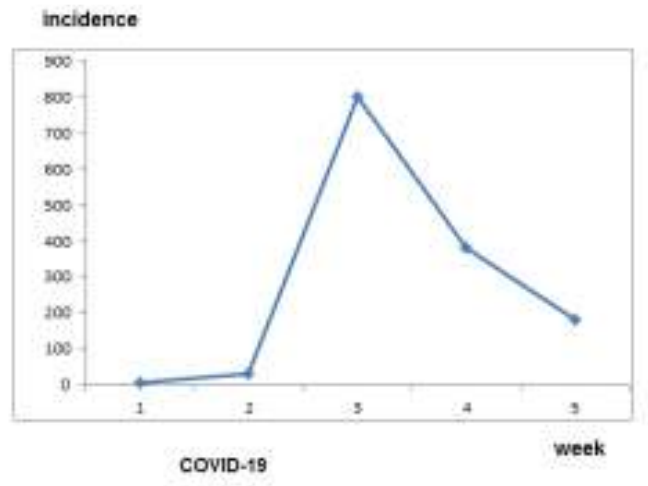

From reappraisal of available data from Thailand ${ }^{1}$, the incidence of rotavirus infection dramatically reduced and reached zero after COVID-19 lock down (Figure 1). Lockdown started in the $9^{\text {th }}$ week of 2020, complete lockdown being used in the first month and partial open/off lockdown in the following months. On the other hand, COVID-19 incidence initially increased after the lockdown before a slower reduction occurred, the incidence never coming down to zero (Figure 1). In fact, lock down decreases the chance of close contact in a crowded environment. School closure is also a common measure which can significantly reduce the chances of children getting diseases from the schools.

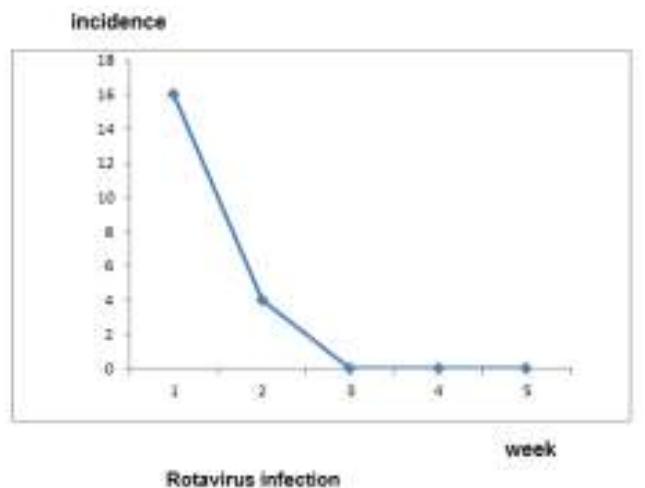

Figure 1: Trend of incidence of rotavirus infection and COVID-19 after COVID-19 lock down

\section{References}

1. Suntronwong N, Thongpan I, Chuchaona W, Lestari FB, Vichaiwattana P, Yorsaeng $\mathrm{R}$, et al. Impact of COVID-19 public health interventions on influenza incidence in Thailand. Pathogens and Global Health 2020; 114(5): 225-7.

https://doi.org/10.1080/20477724.2020.17 77803

PMid: 32521210

2. Gómez-Rial J, Sánchez-Batán S, RiveroCalle I, Pardo-Seco J, Martinón-Martínez $\mathrm{JM}$, Salas A, et al. Rotavirus infection beyond the gut. Infection and Drug Resistance 2018; 12:55-64.

https://doi.org/10.2147/IDR.S186404

PMid: 30636886 PMCid: PMC6307677

\footnotetext{
*Pathum Sookaromdee ${ }^{1}$; Viroj Wiwanitkit ${ }^{2}$

${ }^{1}$ Private Academic Consultant,

${ }^{2}$ Honorary Professor, Dr. DY Patil University, Pune, India

*Correspondence: pathumsook@gamil.com

orcid.org/ 0000-0002-8859-5322
} 